Armitage P. Berry G. Statistical methods in medical research. 2nd ed. Oxford Blackwell Scientific, 1987:117-20, 399-405.

6 Goldacre MJ, Simmons H, Henderson J, Gill LE. Trends in episede based and person based rates of admission to hospital in the Oxford record linkage study area. Br Med f 1988:296:583-5.

7 Hev E. Special care nurseries: admitting to a policy. Br Med $\mathcal{J}$ 1983;287: $152+-7$

8 Wynne J, Hull D. Why are children admitted to hospital? Br Med $f$ 1977; ii: $11+0-2$.

9 Hutchison TP, Durojaive L, Madeley RJ. Improved primary care does not prevent the admission of children to hospital [Abstract]. Arch Dis Child $1987: 62: 6+5-52$.

10 Royal College of General Practitioners, Office of Population Censuses and Surveys, Department of Health and Social Security. Morbidity statistics from general practice. Second national study 1971-2. London: HMSO, 1979. (Studies on medical and population subjects No 26.

11 Royal College of General Practitioners, Office of Population Censuses and Surveys, Department of Health and Social Security. Morbidity statistics from general practice. Third national study 1981-82. London: HMSO, 1986. (Series MB5 No 1.)

12 Anderson HR, Bailey P, West S. Trends in the hospital care of acute childhood asthma 1970-8: a regional study. Br Med f 1980;281:1191-4.
13 Khot A, Burn R, Evans N, Lenney C, Lenney W. Seasonal variation and time trends in childhood asthma in England and Wales 1975-81. Br Med $\mathrm{J}$ 1984;289:235-8.

14 Anderson HR. Is the prevalence of asthma changing? Arch Dis Child 1989:64:172-5.

15 Roval College of Surgeons of England. Guidelines for day case surgery. London: RCS, 1985 .

16 Logan RFL, Ashley JSA, Klein RE, Robson DM. Dynamics of medical care: the Liverpool study into the use of hospital resources. London: London School of Hygiene and Tropical Medicine, 1972. (Memoir 14.)

17 McPherson K. Variations in hospitalisation rates: why and how to study them In: Ham C, ed. Variations in health care: assessing the evidence. London: King's Fund Institute, 1988.

18 Wennberg JE, McPherson K, Caper P. Will payment based on diagnosisrelated groups control hospital costs? $N$ Engl f Med 1984;311:295-300

$19 \mathrm{Kemper} \mathrm{KJ}$. Medically inappropriate hospital use in a pediatric population. N Engl F Med 1988;318:1033-7.

20 Wadsworth $M$. Inter-generational differences in child health. In: Measuring socio-demographic change. London: Office of Population Censuses and Surveys, 1985. (British Society for Population Studies.

\title{
Trial of support treatment with human chorionic gonadotrophin in the luteal phase after treatment with buserelin and human menopausal gonadotrophin in women taking part in an in vitro fertilisation programme
}

\author{
Elaine M Smith, Fred W Anthony, Stephanie C Gadd, Gordon M Masson
}

\begin{abstract}
Objective-To evaluate the effect of support with human chorionic gonadotrophin in the luteal phase in women taking part in an in vitro fertilisation programme after buserelin and human menopausal gonadotrophin were used to hyperstimulate their ovaries.
\end{abstract}

Design-Controlled group comparison.

Setting-Outpatient department of a private hospital.

Patients -115 Women with indications for in vitro fertilisation, all of whom had at least one embryo transferred.

Interventions - After suppression of the pituitary with buserelin the ovaries of all the women were stimulated with human menopausal gonadotrophin on day 4 of the luteal phase. Human chorionic gonadotrophin (10000 IU) was given to induce ovulation, and oocytes were recovered 34 hours later. Embryos were transferred 46 to 48 hours after insemination. Women who had received the 10000 IU of human chorionic gonadotrophin on a date that was an uneven number $(n=61)$ were allocated to receive support doses of $\mathbf{2 5 0 0}$ IU human chorionic gonadotrophin three and six days after that date. The remaining 54 women did not receive hormonal support.

End point-Determination of the rates of pregnancy.

Measurements and main results-Support with human chorionic gonadotrophin did not significantly alter the progesterone or oestradiol concentrations in the early or mid-luteal phase. The mean (range) progesterone concentrations in the late luteal phase in women who did not become pregnant were, however, significantly higher in those who received support $(16(9-110) \mathrm{nmol} / 1 v 8(4-46) \mathrm{nmol} / \mathrm{l})$, and the luteal phase was significantly longer in this group (14 days $v 12$ days). The rate of pregnancy was significantly higher in the women who received support than in those who did not $(25 / 61 v 8 / 54)$.

Conclusions - When buserelin and human menopausal gonadotrophin are used to hyperstimulate ovaries support with human chorionic gonadotrophin in the luteal phase has a beneficial effect on in vitro fertilisation.

\section{Introduction}

The value of providing hormonal support in the luteal phase after hyperstimulation of the ovaries and aspiration of follicles for in vitro fertilisation has been much debated. Adequate production of progesterone by the corpus luteum is necessary for implantation of a zygote and early maintenance of pregnancy.' This may not be achieved either because of follicular aspiration, which by removing granulosa cells during recovery of oocytes may reduce the production of progesterone in the luteal phase or, alternatively, because the dose of human chorionic gonadotrophin given to induce ovulation may not adequately stimulate the corpus luteums. Varygas et al, however, showed that follicular aspiration does not lead to lower progesterone concentrations'; indeed, because of the presence of multiple corpus luteums progesterone concentrations after in vitro fertilisation and transfer of an embryo are higher than in a natural cycle.

Cycles in which conception occurs are associated with higher progesterone concentrations in the luteal phase ${ }^{+}$and in vitro fertilisation regimens often include empirical hormonal support during the luteal phase in an attempt to mimic this hormonal profile. Hyperstimulation regimens consisting of human menopausal gonadotrophin alone or in combination with clomiphene citrate have been followed by supplementation during the luteal phase with progesterone ${ }^{56}$ or human chorionic gonadotrophin, ${ }^{78}$ or both. ${ }^{4}$ Rates of pregnancy showed no significant improvement with these regimens, although in two studies human chorionic gonadotrophin prolonged the luteal phase, ${ }^{111}$ which was thought to exert a beneficial effect as poor rates of pregnancy have been associated with regimens that lead to short luteal phases.'2 Acceptable rates of pregnancy are achieved without hormonal supplementation in the luteal phase..$^{131+}$ Thus there is no clear evidence for a beneficial effect of supplementation.

Treatment with both gonadotrophin releasing hormone agonists and gonadotrophins is an effective 
and more controlled hyperstimulation regimen. Gonadotrophin releasing hormone agonists induce hypogonadotrophism during induction of follicular growth with exogenous gonadotrophins, thus preventing premature luteinisation. ${ }^{16}$ This reversible suppression of the pituitary may influence the adequacy of the luteal phase in establishing a suitable uterine environment for nidation. Some programmes using this form of treatment have given support in the luteal phase either with human chorionic gonadotrophin ${ }^{17}$ or with progesterone, ${ }^{15} 14$ but none have used a control population. We assessed the value of support with human chorionic gonadotrophin in the luteal phase in an in vitro fertilisation programme in which buserelin and human menopausal gonadotrophin were used to hyperstimulate the ovaries.

\section{Materials and methods}

We studied 115 women attending an in vitro fertilisation unit. Each had at least one embryo transferred. The ovaries of all of the women were stimulated with human menopausal gonadotrophin (Pergonal) after suppression of the pituitary with the gonadotrophin releasing hormone agonist buserelin (Suprefact). Buserelin was taken by nasal spray in three doses of 200 ug daily, starting during the luteal phase of the previous cycle and continuing throughout the treatment cycle until human chorionic gonadotrophin (Profasi) was given. Human menopausal gonadotrophin was given ( $300 \mathrm{IU}$ in four ampoules daily) from day 4 of the luteal phase until there were at least two follicles $>17 \mathrm{~mm}$ diameter. Final maturation of oocytes was induced with 10000 IU human chorionic gonadotrophin, and oocytes were recovered 34 hours later.

Blood samples were taken on days 4 and 7 and daily

TABLE I - Indications for in vitro fertilisation in women who did and did not receive human chorionic gonadotrophin (HCG) in luteal phase

\begin{tabular}{lcc}
\hline Indication & $\begin{array}{c}\text { Women who } \\
\text { received HCG } \\
(\mathbf{n}=61)\end{array}$ & $\begin{array}{c}\text { Women who did not } \\
\text { receive HCG } \\
(\mathbf{n}=54)\end{array}$ \\
\hline Factor in partner & 16 & 15 \\
Tubal disease & 29 & 27 \\
Other & 16 & 12
\end{tabular}

*Included mucus hostility, endometriosis, tubal disease and endometriosis, unexplained infertility, and anovulation with no bias.

TABLE II-Median (range) serum oestradiol and progesterone concentrations in women who did and did not receive human chorionic gonadotrophin ( $H C G$ ) in luteal phase and did not become pregnant

\begin{tabular}{lcc}
\hline & $\begin{array}{c}\text { Women who } \\
\text { received HCG } \\
(\mathrm{n}=36)\end{array}$ & $\begin{array}{c}\text { Women who did not } \\
\text { receive HCG } \\
(\mathrm{n}=46)\end{array}$ \\
\hline Oestradiol $(\mathrm{pmol} / \mathrm{l})$ : day 1 & $+225(1350-24500)$ & $4275(1550-17000)$ \\
Day 6 & $3375(1050-16000)$ & $3500(575-12500)$ \\
Progesterone $(\mathrm{nmol} / \mathrm{l})$ : day 1 & $15(6-100)$ & $16(7-54)$ \\
Day 6 & $160(60-74)$ & $170(80-525)$ \\
Day 12 & $16(9-110)$ & $8^{\star}(4-46)$ \\
\hline${ }^{\star}<0.001$. & &
\end{tabular}

TABLE III - Total number of embryos transferred and rate of implantation in women who did and did not receive human chorionic gonadotrophin (HCG) in luteal phase according to how many embryos were transferred to each woman

\begin{tabular}{lccccc}
\hline \multirow{2}{*}{$\begin{array}{l}\text { No of } \\
\begin{array}{l}\text { cmbryos } \\
\text { transferred }\end{array}\end{array}$} & $\begin{array}{c}\text { Total No of embryos } \\
\text { transferred }\end{array}$ & $\begin{array}{c}\text { Total No of embryos } \\
\text { implanted }\end{array}$ & & $\begin{array}{c}\text { Total No of embryos } \\
\text { transferred }\end{array}$ & $\begin{array}{c}\text { Total No of embryos } \\
\text { implanted }\end{array}$ \\
\hline 1 & 5 & 2 & & 4 & 1 \\
2 & 18 & 1 & 74 & 6 \\
3 & 54 & 20 & & 64 & 4 \\
4 & 116 & 36 & 160 & 11 \\
\hline Total & 193 & & &
\end{tabular}

from day 9 after the start of menstruation for estimation of serum oestradiol concentrations. Oocytes were recovered by transvaginal aspiration guided by ultrasonography and were incubated in Hepes buffered Earle's medium (Gibco, United Kingdom) for six hours before insemination. Embryos were transferred 42 to 46 hours after insemination with a Wallace catheter (Wallace, United Kingdom).

Women were allocated to receive support with human chorionic gonadotrophin during the luteal phase depending on the date that the dose of human chorionic gonadotrophin to induce ovulation was given - if the date was an uneven number support was given, if an even number support was not given. Human chorionic gonadotrophin was given to 61 of the 115 women in a dose of $2500 \mathrm{IU}$ three and six days after the dose of $10000 \mathrm{IU}$ given to induce ovulation. All of the women were informed and their consent obtained.

Blood samples were also taken one, six, and 12 days after the dose of 10000 IU human chorionic gonadotrophin for estimation of serum oestradiol and progesterone concentrations. These were measured by commercially available radioimmunoassays (Serono Diagnostics and Amersham International, respectively).

\section{Results}

The mean (SD) age of the women who received support with human chorionic gonadotrophin was $32 \cdot 2$ $(4 \cdot 0)$ years compared with $31.9(4 \cdot 8)$ in those who did not receive support. The indications for in vitro fertilisation were similar to both groups (table I). Thirty three of the women who received support were having their first attempt at in vitro fertilisation compared with 36 of those who did not receive support.

The median serum oestradiol concentrations did not differ significantly between the two groups (MannWhitney test) on either day 1 or day 6 in cycles in which conception did not occur after the dose of $10000 \mathrm{IU}$ human chorionic gonadotrophin (table II). In addition, no difference was seen between the serum progesterone concentrations on day 1 or day 6 of the luteal phase (table II). There was no significant difference between the groups in the ratio of oestradiol to progesterone concentrations on either day 1 or day 6 . On day 12 , however, the serum progesterone concentration was significantly higher in the women who received support with human chorionic gonadotrophin (16 (9$110) \mathrm{nmol} / \mathrm{l} v 8(4-46) \mathrm{nmol} / \mathrm{l}, \mathrm{p}<0 \cdot 001$ ) (table II). The luteal phase in women who did not become pregnant was significantly longer in those who were given support ( 14 days $v 12$ days, $\mathrm{p}<0 \cdot 001, t=4 \cdot 6$ ).

No significant differences in oestradiol concentrations before ovulation was induced and on days 1 and 6 of the luteal phase (table II) were found between women who became pregnant and those who did not, whether or not support with human chorionic gonadotrophin was given. Progesterone concentrations were also not significantly different on days 1 and 6 , and no significant difference was seen in the ratio of oestradiol to progesterone concentrations (Mann-Whitney test). Support in the luteal phase did not produce significant differences in the median (range) progesterone concentrations on day 12 in the cycles in which conception occurred $(125(23-350) \mathrm{nmol} / \mathrm{l}$ in those who received support $v 85(12-110) \mathrm{nmol} / \mathrm{l}$ in those who did not).

Evidence of a gestation sac on ultrasonography was necessary for pregnancy to be diagnosed-that is, pregnancies detected only by biochemical tests were excluded. The rate of pregnancy was significantly higher in the women who received support with human chorionic gonadotrophin $(25 / 61(41 \%) v 8 / 54(15 \%)$, $\mathrm{p}<0.01)$. The mean number of embryos transferred was similar $(3 \cdot 16 v 2 \cdot 91)$. 
Table III shows the number of embryos that implanted in relation to the number that were transferred. The rate of implantation in the women who received support was consistently higher for one, two, three, or four embryos transferred. The same team of clinician and embryologist recovered all oocytes and transferred all embryos.

Among the women who received support treatment 24 babies were delivered, including five sets of twins and one set of triplets; one stillbirth, three first trimester abortions, and one ectopic pregnancy occurred, and the attempted selective reduction of a quadruplet pregnancy resulted in a complete abortion. Two pregnancies were continuing at the time of writing. Among those who did not receive support with human chorionic gonadotrophin three babies were delivered and three abortions (including two sets of twins) and one ectopic pregnancy occurred. One further twin pregnancy was induced at 28 weeks after the death of the second twin, the first having died at 18 weeks.

\section{Discussion}

The need for hormonal support in the luteal phase after ovarian stimulation with clomiphene citrate and human menopausal gonadotrophin has been much debated. ${ }^{2+1+211}$ Randomised trials have failed to show a significant difference in the rate of pregnancy between women who received support and those who did not. ${ }^{1121}$

We attempted to ascertain whether support with human chorionic gonadotrophin in the luteal phase was necessary when the luteinising hormone releasing hormone analogue buserelin and human menopausal gonadotrophin were used to stimulate the ovaries. A significantly increased rate of pregnancy was found when cycles were supported. There was no biochemical evidence during the early and mid-luteal phase to account for this improvement. Oestradiol and progesterone concentrations during cycles in which conception occurred were not significantly different between cycles that were supported and cycles that were not. Biochemical evidence in the late luteal phase, however, indicated the role of human chorionic gonadotrophin in supplementation of the luteal phase. Non-pregnant women who received support (in whom a valid comparison could be made) had significantly raised progesterone concentrations on day 12 of the luteal phase (table II), suggesting that it is at this point that human chorionic gonadotrophin exerts its beneficial effects.

The raised progesterone concentrations in women who received support with human chorionic gonadotrophin add weight to previous findings of inadequate production of progesterone during the late luteal phase in women stimulated with buserelin and human menopausal gonadotrophin who did not receive support. Smitz et al observed a dramatic decline in serum progesterone concentration from day 8 after the dose of human chorionic gonadotrophin to induce ovulation in 10 women who did not become pregnant." Moreover, in another study only one pregnancy resulted from 13 unsupported cycles compared with 29 pregnancies from 91 cycles when hormonal support in the luteal phase was given.

Pregnancy after hyperstimulation with clomiphene citrate and human menopausal gonadotrophin has been associated with a lower ratio of oestradiol to progesterone concentrations in the luteal phase,,$^{2324}$ suggesting that support during the luteal phase may relieve the contraceptive effect of the high oestradiol concentrations after ovulation. Despite showing a significant decrease in the ratio of oestradiol to progesterone concentration's with support with human chorionic gonadotrophin Buvat et al did not show any improvement in the rate of pregnancy." In contrast, our study showed no influence of support with human chorionic gonadotrophin on the ratio of oestradiol to progesterone concentrations but showed a significantly higher rate of pregnancy.

The luteal phase is extended when support with human chorionic gonadotrophin is given, ${ }^{10}$ as our study confirmed. Cycles in which conception did not occur were significantly longer when human chorionic gonadotrophin was given (mean 14 days $v 12$ days). The main result of our study was the difference produced in the rates of pregnancy. Among women receiving support with human chorionic gonadotrophin the rate of pregnancy was $41 \%$ for each embryo transfer compared with $15 \%$ among women who did not receive support.

In in vitro fertilisation programmes buserelin is stopped before the dose of human chorionic gonadotrophin required to induce ovulation. Although the metabolism of buserelin from the circulation is rapid, the reserve of gonadotrophin in the pituitary has been shown to be inadequate by a highly specific assay for luteinising hormone that uses monoclonal antibodies, which showed that serum luteinising hormone was absent until 12 days after buserelin was stopped. ${ }^{25}$ This finding was confirmed by Smitz et al, who gave boluses of luteinising hormone releasing hormone to women seven days after they stopped treatment with a gonadotrophin releasing hormone agonist; their results showed inadequate gonadotrophic responses. ${ }^{2}$

We conclude that the more adequate late luteal phase and the significant increase in the rate of pregnancy among women given support treatment in this study suggest that support with human chorionic gonadotrophin when buserelin is used with human menopausal gonadotrophin for ovarian hyperstimulation has a beneficial effect on in vitro fertilisation.

We thank Mrs Irene Pace for technical help and Miss Karen Creed for secretarial help.

1 Csaps) AI, Pulkkinen MO, Ruttner B, Saurage JP, W'eist W'(i. Th significance of the human corpus luteum in pregnancy maintenance. $A m f$ Obstet (Bynecol 1972:112:1061-7.

2 Varygas J, Kletzky $O$, Marrs RP. The effect of laparoscopic follicula aspiration on ovarian steroidogenesis during the early preimplantation period. Fertil Steril 1986;45:221-5.

3 Huang K-E, Muechler EK, Schwarz KR, Goggin M, Graham MC. Serum progesterone levels in women treated with human menopausal gonadotrophin and human chorionic gonadotrophin for in vitro fertilisation. Fertil Steril 1986;46:903-6.

+ Jones HW, Acosta AA, Andrews MC, et al. Three vears of in-vitro fertilisation at Nofolk. Fertil Steril 1984;42:826-34.

5 Dlugi AM, Laufer N, Botero-Ruiz W, et al. Altered follicular development in clomiphene citrate versus human menopausal gonadotrophin-stimulated crcles for in-vitro fertilisation. Fertil Steril 1985;43:40-7.

6 Muasher S, Acosta AA, Garcia JE, Jones GS, Jones HW. Luteal phase serum oestradiol and progesterone in in-vitro fertilisation. Fertil Steril 1984;41 $838-43$

7 Mahadevan MM, Leader A, Taylor PJ. Effects of low dose human chorionic gonadotrophin on corpus luteum function after embryo transfer. F In l'itro Ferl Embrovo Transfer 1985;2:190-4.

8 Cedard L, Guichard A, Janssens Y, Tanguy G, Boyer P, Zorn JR Progesterone and o'stradiol in saliva after in vitro fertilisation and embro transfer. Fertil Steril 1987;47:278-83.

9 Forman R, Fries N, Testart J, Belaisch-Allart J, Hazaut A, Frydman R. Evidence for an adverse effect of elevated serum oestradiol concentrations on embrio implantation. Fertil Steril 1988:49:118-22.

10 Bavk CM, McBain JC, Clarke GA, et al. Ovarian stimulation regimens in an in vitro fertilisation programme: a comparative analysis. Ann NY Acad Scl 1985:442:123-7

11 Buvat J, Marcolin G, Herbaut J-C, Dehaene J-L, Verbery P, Fourlinnie JC. A randomised trial of human chorionic gonadotrophin support following in vitro fertilisation and embryo transfer. Fertil Steril 1988;49:458-61.

12 Quigley MM. Selection of agents for enhanced follicular recruitment in an in vitro fertilisation and embryo replacement treatment programme. Ann NY Acad Sci 1985;442:96-111.

13 Russell JB, Polan ML, DeCherney AH. The use of pure follicle stimulating hormone for ovulation induction in normal ovulatory women in an in vitro fertilisation programme. Fertil Steril 1986;45:829-33.

1+ Van Steirteghem AC, Smitz J, Camus M, et ul. The luteal phase after in-vitro fertilisation and related procedures. Hum Reprod 1988;3:161-4.

15 Rutherford AJ, Subak-Sharpe RJ, Dawson KJ, Margara RA, Franks S,

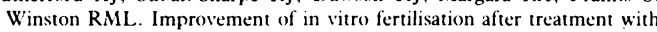
buserelin, an agonist of luteinising hormone releasing hormone. Br. Med $\mathcal{J}$ 1988:296:1765-8. 
16 Fleming R, Coutts JRT. Induction of multiple follicular growth in normally menstruating women with endogenous gonadotrophin suppression. Fertil Steril 1986; $45: 226-30$

17 Neveu S, Hedon B, Bringer J, el al. Ovarian stimulation by a combination of a gonadotrophin releasing hormone agonist and gonadotrophins for in vitro fertilisation. Fertil Steril 1987;47:639-43.

18 Zorn JR, Barata M, Brami C, et al. Ovarian stimulation for in vitro fertilisation combining administration of gonadotrophins and blockade of the pituitary with D-Trp"-LHRH microcapsules: pilot studies with two protocols. $H$ um Reoprod 1988:3:235-9.

19 Serafini P, Stone B, Kerin J, Batzofin J, Quinn P, Marrs RP. An alternate approach to controlled ovarian hyperstimulation in "poor responders": pretreatment with a gonadotrophin-releasing hormone analog. Fertil Steril pretreatment

20 Zarutskie P'W', Kuzan FB, Dixon L, Soules MIR. Endocrine changes in the late follicular and post-ovulatory intervals as determinants of the in-vitro fertilisation pregnancy rate. Fertil Steril 1986;47:137-43.

21 Trounson A, Howlet D, Rogers P, Hoppen H-O. The effect of progesterone supplementation around the time of oocyte recovery in patients superovulated for in-vitro fertilisation. Fertil Steril 1986;45:532-5.

22 Smitz J, Devraey P, Camus $M$, et al. The luteal phase and early pregnancy after combined GnRH-agonis/human menopausal gonadotrophin treatment for superovulation in in-vitro fertilisation or gamete intrafallopian transfer. Hum Reprod 1988;3:585-90.

23 O'Neill C, Pike IL, Porter RN, Gidley-Baird A, Sinosich MJ, Saunders DM. Maternal recognition of pregnancy prior to implantation: methods for monitoring embryonic viability in vitro and in vivo. Ann NY Acad $S$ 1985;442:429-39.

24 Gidley-Baird AA, O'Neill C, Sinosich MJ, Porter RN, Pike IL, Saunders DM. Failure of implantation in human in vitro fertilisation and embryo transfer patients: the effects of altered progesterone/oestrogen ratios in humans patients: the effects of altered progest

25 Sandow J, Englebart K, von Reckenberg W. The different mechanisms for suppression of pituitary and testicular function. Med Biol 1985;63:192-200.

(Accepled 22 Murch 1989

\title{
Perimenopausal risk of falling and incidence of distal forearm fracture
}

\author{
S J Winner, C A Morgan, J Grimley Evans
}

\begin{abstract}
A postal survey of 2000 women and 2000 men sampled from the electoral roll in Oxford was undertaken to ascertain whether changes with age in the risk of falling might explain the stepwise increases in age specific incidence rates of distal forearm fracture which occur in women at around the age of 50. Corrected response rates were $83 \%$ for women and $72 \%$ for men. In women, but not in men, there was a rise in the risk of falling from 45 years, peaking in the 55-59 year age group, and sinking to a nadir at ages 70-74. In both sexes rates rose in extreme old age. These variations were not attributable to preferential response from people who had suffered a fracture.

It is concluded that changes in the risk of falling interact with osteoporosis to produce a perimenopausal rise in the incidence of forearm fractures and contribute to the fluctuations in incidence of these fractures in old age.
\end{abstract}

\section{Introduction}

In women the age specific incidence of fractures of the distal forearm rises steeply between the age groups 40-44 and 55-59 but thereafter shows no consistent further increase (see figure). ${ }^{12}$ The incidence in men is constant with age. This pattern is conventionally attributed entirely to perimenopausal osteoporosis in women increasing the likelihood that a fracture will result if a fall occurs, but the frequency of falls among women during their middle years has not been examined. We carried out a postal survey to examine the possibility that an increase in the frequency of falls in middle age might contribute to the steep rise in incidence of distal forearm fracture in women at this time of life.

University Division of

Geriatric Medicine, The

Radcliffe Infirmary, Oxford

OX2 6HE

S J Winner, MRCP, clinical

lecturer

C A Morgan, FRACP, visiting fellow

J Grimley Evans, FRCP, professor

Correspondence to: Dr Winner.
A postal questionnaire designed for self completion was sent to 2000 women residents of Oxford city, selected at random from the 1986 electoral register in postcode districts OX1-4. Subjects were asked for age

\section{Subjects and methods}

The age and sex of all residents of Oxford city who suffered a fracture of the distal forearm during 1986 were identified from the fracture clinic records at the John Radcliffe hospital to confirm that the local epidemiological pattern was broadly similar to that at last birthday and for "yes" or "no" answers to questions used in a previous survey": "Have you had any falls in the last year?" and "If so, did you break any bones in your falls?" Local press and radio coverage was organised without disclosing the hypothesis being tested. To assess response bias 500 initial non-responders were sent a second copy of the questionnaire after four weeks. A similar study was undertaken of men identified from the 1988 electoral register.

\section{Results}

A total of 124 fractures of the distal forearm were identified in Oxford city residents age 20-74. Estimated age specific yearly incidence rates (table I) showed the expected stepwise increase in middle aged women and not in men.

\section{FALLS AND FRACTURES}

Women-Replies were received from 1335 women. After allowing for an estimated $19 \cdot 2 \%$ obsolescence in the 1986 electoral register at the time of the survey the crude response rate of $67 \%$ corrected to roughly $83 \%$. Ten respondents gave insufficient information and 16 were under 20 , leaving 1309 women; of these 286 $(22 \%)$ reported falling, of whom 30 suffered a fracture. The 1141 initial responders and 168 who responded to the second mailing did not differ significantly in the

TABLE I-Numbers and yearly incidence rates of distal forearm fracture in Oxford, 1986

\begin{tabular}{|c|c|c|c|c|}
\hline \multirow[b]{2}{*}{$\begin{array}{l}\text { Age group } \\
\text { (years) }\end{array}$} & \multicolumn{2}{|c|}{ Women } & \multicolumn{2}{|c|}{ Men } \\
\hline & $\begin{array}{c}\text { No of } \\
\text { fractures }\end{array}$ & $\begin{array}{c}\text { Yearly } \\
\text { incidence } \\
\text { (per 10000) }\end{array}$ & $\begin{array}{c}\text { No of } \\
\text { fractures }\end{array}$ & $\begin{array}{c}\text { Yearly } \\
\text { incidence } \\
\text { (per } 10000)\end{array}$ \\
\hline $20-24$ & 6 & $12 \cdot 8$ & 12 & $25 \cdot 6$ \\
\hline $\begin{array}{l}25-29 \\
30-34\end{array}$ & $\left.\begin{array}{l}3 \\
5\end{array}\right\}$ & $11 \cdot 4$ & $\left.\begin{array}{l}2 \\
1\end{array}\right\}$ & $4 \cdot 1$ \\
\hline $\begin{array}{l}35-39 \\
40-44\end{array}$ & $\left.\begin{array}{l}2 \\
3\end{array}\right\}$ & $9 \cdot 8$ & $\left.\begin{array}{l}4 \\
1\end{array}\right\}$ & $10 \cdot 0$ \\
\hline $\begin{array}{l}45-49 \\
50-54\end{array}$ & $\left.\begin{array}{l}3 \\
7\end{array}\right\}$ & $21 \cdot 1$ & $\left.\begin{array}{l}4 \\
1\end{array}\right\}$ & $10 \cdot 3$ \\
\hline $\begin{array}{l}55-59 \\
60-64\end{array}$ & $\left.\begin{array}{l}15 \\
16\end{array}\right\}$ & $60 \cdot 2$ & $\left.\begin{array}{l}3 \\
0\end{array}\right\}$ & $6 \cdot 5$ \\
\hline $\begin{array}{l}65-69 \\
70-74\end{array}$ & $\left.\begin{array}{l}17 \\
16\end{array}\right\}$ & $62 \cdot 0$ & $\left.\begin{array}{l}1 \\
2\end{array}\right\}$ & $7 \cdot 3$ \\
\hline
\end{tabular}

